\title{
A CRÍTICA FEMINISTA NO CENÁRIO LITERÁRIO CONTEMPORÂNEO
}

\author{
SANT'ANA, Renata Cristina ${ }^{1}$ \\ ROCHA, Enilce do Carmo Albergaria ${ }^{2}$
}

\begin{abstract}
RESUMO: Buscamos, neste estudo, apresentar parte do arcabouço teórico construído por escritoras e pesquisadoras ligadas à crítica e à produção literária de autoria feminina (WOOLF, 2016; DUARTE, 2009, 2016, 2019; SCHMIDT, 2019; ZOLIN, 2009; RIBEIRO, 2017; FUNCK, 2016). Procuramos demonstrar as contribuições teóricas oferecidas pela crítica feminista ao campo literário no que se refere ao rompimento com o estatuto do silenciamento feminino que tratou de posicionar as mulheres como seres passivos diante das determinações do poder masculino. Ao considerar a atuação feminina no âmbito literário, discute-se o lugar do discurso produzido pelas escritoras e sua função enquanto dispositivo utilizado para subverter os modelos definidores dos papéis sociais construídos a partir da categoria de gênero.
\end{abstract}

PALAVRAS-CHAVE: Teoria crítica feminista, literatura, autoria feminina.

\section{FEMINIST CRITICISM IN THE CONTEMPORARY LITERARY SCENE}

\begin{abstract}
In this study, we look for presenting part of the theoretical framework that has been constructed by female writers and researchers who are connected to the criticism and to the literary production of female authorship (WOOLF, 2016; DUARTE, 2009, 2016, 2019; SCHMIDT, 2019; ZOLIN, 2009; RIBEIRO, 2017; FUNCK, 2016). We look for demonstrating the theoretical contributions offered by the feminist criticism to the literary field, regarding the disruption of the status of female silencing that has positioned women as passive beings in the face of determinations by male power. By considering the female acting within the literary scope, there is a discussion about the
\end{abstract}

\footnotetext{
${ }^{1}$ Doutoranda em Letras - Estudos Literários pela Universidade Federal de Juiz de Fora.

${ }^{2}$ Doutora em Letras e professora da Universidade Federal de Juiz de Fora. 


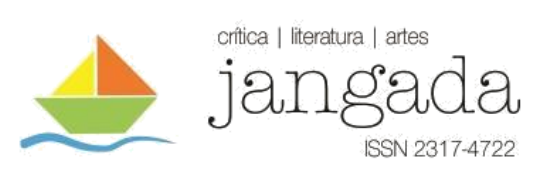

standpoint of the discourse that is produced by female writers and its function as a device used to subvert the models that define social roles that are constructed from the gender category.

KEYWORDS: Feminist criticism, literature, women-authored novels.

"Minha profissão é a literatura", afirmou Virginia Woolf (2016, p. 09) em seu discurso para a Sociedade Nacional de Auxílio às Mulheres em 1931, rememorando o fato de que muitas mulheres vieram antes dela, abrindo caminhos em direção à conquista de direitos básicos como os de ler e escrever, que, durante séculos, lhes haviam sido negados. Neste discurso, Woolf (2016) relata que na época em que começou a escrever, primeiro como redatora de artigos para jornais, já não havia mais tantos obstáculos impedindo-a de prosseguir na carreira de escritora, então aceita como "respeitável e inofensiva" (WOOLF, 2016, 10). Porém, ao se deparar com uma situação em que haveria de escrever uma resenha sobre um romance de um famoso escritor, Woolf viu-se na condição de ter que enfrentar um fantasma, que, por sinal, era uma mulher, a qual decidiu chamar de "Anjo do Lar"3. Em seu relato, Woolf expressa o incômodo que sentia em relação a essa mulher toda vez ela aparecia para assombrá-la em seu ofício de escrever:

Era ela que costumava aparecer entre mim e o papel enquanto eu fazia as resenhas. Era ela que me incomodava, tomava meu tempo e me atormentava tanto que no fim matei essa mulher. [...] Ela era extremamente simpática. Imensamente encantadora. Totalmente altruísta. Excelente nas difíceis artes do convívio familiar. Sacrificava-se todos os dias. Se o almoço era frango, ela ficava com o pé, se havia ar encanado, era ali que ia se sentar - em suma, seu feitio era nunca ter opinião ou vontade própria, e preferia sempre concordar com as opiniões e vontades dos outros. E acima de tudo - nem precisava dizer - ela era pura. Sua pureza era tida como sua maior beleza - enrubescer era seu grande encanto (WOOLF, 2016, p. 10-11).

Deu-se que, enquanto Woolf resenhava sobre o romance do tal escritor famoso, o Anjo do Lar apareceu para lhe assombrar aconselhando-a: "Seja afável; seja meiga; lisonjeie; engane; use todas as artes e manhas de nosso sexo. Nunca deixe ninguém perceber que você tem opinião

\footnotetext{
${ }^{3}$ O nome escolhido faz referência à heroína de um poema de Coventry Patmmore (1823-1896) que celebrava o amor conjugal e idealizava o papel doméstico das mulheres.
}

Jangada | nr. 15, jan/jun, 2020 | ISSN 2317-4722

$61 \mid$ Pá g in a 


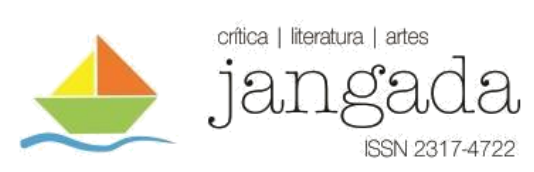

própria” (WOOLF, 20016, p. 12). Alegando legítima defesa, narra Virginia Woolf que partiu pra cima dela e, agarrando-a pela garganta, deu-lhe um merecido fim: "Se eu não a matasse, ela é que me mataria. Arrancaria o coração da minha escrita" (WOOLF, 2016, p. 13). Porém, devido à sua natureza fictícia, ela demorou para morrer, e, vez ou outra, reaparecia para atormentá-la, afinal, "é muito mais difícil matar um fantasma do que uma realidade" (WOOLF, 2016, p. 13).

No final, depois de muitos combates e orgulhosa da luta, venceu a escritora, reconhecendo que matar o Anjo do Lar era parte do seu ofício. Assim, livre do fantasma da falsidade do Anjo do Lar, a mulher escritora poderia finalmente ser ela mesma. Eis que surge a grande questão "mas o que quer dizer ser "ela mesma?" (WOOLF, 2016, p. 14). Esse questionamento nos coloca de frente com a diversidade das experiências responsáveis por construir as subjetividades e as identidades femininas, afastando a concepção essencializante que, por muito tempo, norteou a compreensão sobre o feminino, ironicamente convencionado pelo discurso hegemônico masculino do patriarcado. Extirpadas as perturbações causadas pelo fantasma do Anjo do Lar, novos fantasmas não tardaram a surgir, desta vez relacionados às experiências das mulheres frente aos muitos preconceitos que se apresentavam e que precisariam ser enfrentados e combatidos também. A esse respeito, Virginia Woolf havia alertado: “ainda vai levar muito tempo até que uma mulher possa se sentar e escrever um livro sem encontrar um fantasma que precise matar, uma rocha que precise enfrentar" (WOOLF, 2016, p. 17). Diante da condição apontada pela escritora, nos perguntamos: Em se tratando de literatura produzida por mulheres, o que vemos em cena hoje, em pleno século XXI? Antes de responder a esta pergunta, é necessário manter o nosso olhar ainda voltado para o passado, a fim de retomar o movimento de inserção das mulheres no universo letrado brasileiro e o percurso por elas realizado para que possamos compreender a trajetória das mulheres no mundo das letras e como se deram as articulações e os movimentos que lhes possibilitaram superar, hoje, o silenciamento e o apagamento que a tradição literária por séculos lhes relegou.

Durante muito tempo, devido às diferenças biológicas e sexuais, coube às mulheres a incumbência da procriação e da reprodução da espécie humana, de modo que foram reconhecidas apenas como seres de natureza, ao passo que para os homens reservaram-se as condições para a criação e produção, dado o seu reconhecimento como seres de cultura. Consideradas as diferenças sexuais, estabeleceu-se a divisão das funções e dos papéis sociais a serem desempenhados pelos indivíduos na sociedade: para a mulher ficou definido que, em razão da sua capacidade de gerar e nutrir, deveria, incondicionalmente, assumir para si a Jangada | nr. 15, jan/jun, 2020 | ISSN 2317-4722 62 | P á g in a 


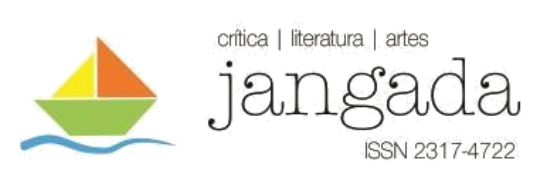

maternidade, que implicaria, necessariamente no casamento. Logo, estabelecia-se para os indivíduos do sexo feminino uma vida destinada à reprodução, aos cuidados com a família e às tarefas domésticas configuradas dentro dos limites da esfera da vida privada. Aos homens, por sua vez, caberia o trabalho em suas mais diversas formas de ocupação e o estabelecimento de relações sociais, econômicas e políticas para além dos limites da família, o que acabou por determinar o espaço público como lugar de atuação masculina. Está fundada assim, a ordem social patriarcal que, há séculos, vem norteando a construção de valores e de visões de mundo que orientam condutas e formam subjetividades a partir do estabelecimento de relações assimétricas de poder diretamente relacionadas à diferença de gênero.

De acordo com Constância Lima Duarte (2009), muitos foram os que insistiram na incapacidade física e mental das mulheres, julgavam-nas desinteressadas pela política e apregoavam que a desarmonia do lar seria instaurada caso o direito ao voto e ao trabalho remunerado fosse concedido às mulheres. Frente a esta situação, a constituição da identidade feminina, como observado no contexto acima descrito, ocorreu a partir de formulações e considerações masculinas, carregadas de preconceitos e ideologias. Segundo Duarte, "foi necessário esperar que as mulheres tomassem a palavra, se impusessem no espaço público e pudessem, por fim, construir as próprias representações" (DUARTE, 2009, p. 31). Conscientes da condição desvantajosa a que, durante séculos, viveram submetidas, praticamente confinadas no espaço privado do lar, muitas mulheres do início do século XIX decidiram se organizar na luta pelo direito básico de aprender a ler e a escrever, apostando na educação como uma via de acesso e de admissão no espaço público. Em meio à busca pelo reconhecimento intelectual e pela participação na vida pública, ocorreram muitos eventos importantes que não aparecem na história oficial, de modo que muitas vozes femininas, importantes na história da luta por direitos, foram silenciadas, muitos nomes foram esquecidos e imagens foram apagadas, deixando uma lacuna a ser preenchida na história da inserção das mulheres no universo letrado brasileiro ${ }^{4}$.

\footnotetext{
${ }^{4}$ A respeito dos jornais e revistas que circularam no Brasil no século XIX e que tinham a mulher não só como público alvo, mas também como autoras, ver: DUARTE, Constância Lima. A imprensa feminina e feminista no Brasil: Século XIX. Belo Horizonte: Autêntica, 2016. A obra apresenta um painel onde ressurgem 143 jornais e revistas que alcançaram amplitude no território nacional, levando reflexões sobre as polarizações então vigentes quanto o papel da mulher na sociedade da época. Enquanto parte da sociedade se empenhava em acompanhar as mudanças do mundo moderno na defesa do direito das mulheres à educação, alguns ainda insistiam na estagnação, na ignorância e na dependência da mulher reforçando a condição de submissão, inferioridade, domesticidade e fragilidade. A obra, que é fruto de uma longa pesquisa sobre a história das mulheres e do movimento feminista no Brasil, apresenta muitas fontes primárias raras ou de difícil acesso.
} 
Em relação à conquista do direito à educação, a primeira legislação autorizando a abertura de escolas femininas data de 1827. Segundo Duarte e Paiva:

Conquistado o direito de se educar e de educar outras, as mulheres precisavam ainda ultrapassar fronteiras que as limitavam a um universo mais restrito aos alargamentos dos papéis de mãe e de boa esposa. A literatura foi uma forma encontrada por elas para ampliar sua participação na vida pública, primeiro por meio de um espaço semipúblico, os salões de poesia, saraus realizados nas residências de intelectuais e figuras da elite brasileira. Depois, pela participação em eventos do cenário cultural e literário e por sua crescente publicação em jornais e revistas especializadas (DUARTE; PAIVA. 2009, p. $13)$.

Conforme apontam os estudos das autoras acima citadas, o magistério, os salões literários e os periódicos da época funcionaram como instâncias importantes para a entrada da figura feminina no meio intelectual. De acordo com Duarte,

as primeiras mulheres que tiveram acesso à educação tomaram para si a tarefa de estender os benefícios do conhecimento às demais companheiras e abriram escolas, publicaram livros, enfrentaram a opinião corrente de que mulher não necessitava saber ler nem escrever (DUARTE, 2019, p. 27).

Através do acesso à educação e ao conhecimento, as mulheres viram na literatura um caminho para o convívio social e para a mobilidade em um espaço que, rigorosamente, lhes havia sido negado - o espaço público. Assim, engajadas na luta pelo direito à educação e escrevendo em jornais e revistas, surgiram as primeiras escritoras e intelectuais brasileiras, dentre elas aquela que é tida como precursora do feminismo no Brasil, a escritora, educadora e abolicionista Nísia Floresta ${ }^{5}$. Frente a estes fatos constata-se que:

No século XIX, as mulheres que escreveram, que desejaram viver da pena, que desejaram ter uma profissão de escritoras, eram feministas, pois só o

\footnotetext{
${ }^{5}$ Segundo Constância Lima Duarte (2019, p. 28), Nísia Floresta (RN, 1810-1885) teria sido umas das primeiras escritoras a publicar em jornais da chamada "grande" imprensa. Seu primeiro livro, Direitos das mulheres e injustiça dos homens (1832) é o primeiro no Brasil a tratar da temática. Trata-se de uma livre tradução da obra Vindication of the rights of woman de Mary Wollstonecraft.
}

Jangada | nr. 15, jan/jun, 2020 | ISSN 2317-4722 


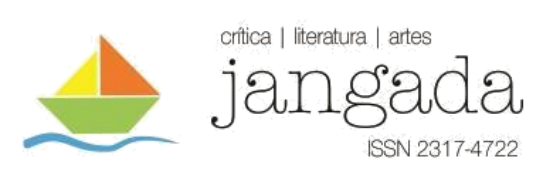

desejo de sair do fechamento doméstico já indicava uma cabeça pensante e um desejo de subversão. E eram ligadas à literatura. Então, na origem, a literatura feminina no Brasil esteve ligada sempre a um feminismo incipiente (Zahidé Muzart apud DUARTE, 2019, p. 27).

A escrita de mulheres contribuiu para uma mudança de paradigma colaborando para o necessário deslocamento do lugar e da função social designados a elas, o que contribuiu também para o processo de desconstrução de uma falsa imagem construída em torno de um modelo essencializante de identidade feminina.

Para Terezinha Rita Schmidt (2019), a invisibilidade da autoria feminina no século XIX é um exemplo do modo como o poder simbólico se exerceu na construção da identidade cultural brasileira, pois, segundo a autora, as figuras masculinas (do intelectual, do crítico e do escritor) definiram o lugar do sujeito que fala em nome da cultura e da cidadania a partir de uma lógica de cunho universalista, que ignorou outras vozes não hegemônicas, como a das mulheres. Nesse sentido, a autoria feminina surge como forma de rompimento com o discurso hegemônico masculino e desafia o monopólio da cultura, da história e da autoridade intelectual. De acordo com Schmidt (2019):

Os textos de autoria de mulheres levantam interrogações acerca de premissas críticas e formações canônicas, bem como tensionam as representações dominantes calcadas no discurso assimilacionista de um sujeito nacional não marcado pela diferença. A hegemonia desse sujeito sempre esteve calcada em formas de exclusão de outras vozes, outras representações (SCHMIDT, 2019, p. 66).

Ao discorrer sobre a importância da literatura do séc. XIX para o processo de elaboração de uma narrativa simbólica que desse conta de traduzir a independência política e as particularidades culturais da nação emergente, Schmidt (2019) demonstra os valores hegemônicos sobre os quais os pensadores e escritores da época se pautaram para produzir uma literatura de cunho nacionalista contendo os elementos definidores da identidade nacional. Em consonância com o crítico Antonio Candido em sua obra Formação da Literatura Brasileira, Schmidt afirma que "construir uma nação significava constituir uma literatura própria" (SCHMIDT, 2019, p. 66). Do empenho em se construir uma narrativa de nação que expressasse 


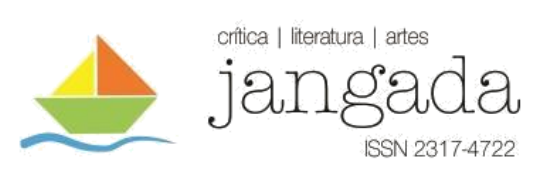

a imagem e a ideia de autonomia, coesão e unidade nasceram os textos fundadores da literatura brasileira, reconhecidos como o cânone literário. De acordo com Schmidt (2019), a representatividade conferida por este cânone à narrativa nacional optou por lançar luz em determinadas memórias e identidades, ignorando e deixando de fora tantas outras, o que resultou no silenciamento e no apagamento de muitas vozes importantes como das mulheres, negros e indígenas.

Alinhado ao projeto literário romântico, o processo de construção da identidade nacional ignorou a alteridade em cumplicidade com o modelo cultural dominante circunscrito nos limites de uma lógica essencialista e etnocentrista do colonizador europeu. De acordo com Schmidt:

\begin{abstract}
A explicação histórica da nação se consolida nas bases de uma ordem social simbólica pautada na imagem da integralidade de um sujeito nacional universal, cuja identidade se impõe de forma abstrata, dissociada de materialidades resistentes como raça, classe e gênero, as quais representam a ameaça da diferença não só às premissas daquele sujeito, presumidamente uniforme e homogêneo, mas ao próprio movimento de sua construção na produção da nação como narração (SCHMIDT, 2019, p. 69).
\end{abstract}

O que se observa ao longo da construção da narrativa nacional no séc. XIX é uma produção literária que se desenvolve com vistas a uniformizar a cultura nacional no intuito de alcançar um padrão determinado para a almejada identidade hegemônica. Esse trabalho, no entanto, não passava de transferência cultural resultada de um certo processo de aculturação somado às imposições de valores e visão de mundo do colonizador europeu que ignorou a presença feminina, assim como a dos povos nativos e dos povos africanos que foram arrancados de seu continente para serem escravizados do outro lado do Atlântico, neste canto do Novo Mundo, chamado hoje Brasil.

A preocupação revisionista e o questionamento sobre os escritos do passado têm funcionado como estratégia para a construção da crítica literária feminista a fim de frear a propagação do discurso, muitas vezes, falacioso, construído e difundido pela tradição. Sobre a completa indiferença em relação às mulheres na elaboração da narrativa da nação, Schmidt escreve:

As mulheres, desde sempre destituídas da condição de sujeitos históricos, políticos e culturais, jamais foram imaginadas e sequer convidadas a se Jangada | nr. 15, jan/jun, 2020 | ISSN 2317-4722 66 | P á g in a 


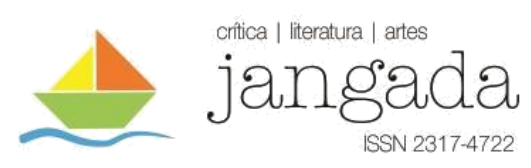

imaginarem como parte da irmandade horizontal da nação, e, tendo seu valor atrelado à capacidade reprodutora, permaneceram precariamente outras para a nação (SCHMIDT, 2019, p. 68).

A busca por conhecer os escritos do passado tem se dado com intuito de romper com o seu julgo para poder instaurar uma nova ordem discursiva, com novas imagens e linguagens formadas a partir da perspectiva de novos sujeitos, capazes de representar as múltiplas identidades femininas no tempo e no espaço. Nesse sentido, revisar criticamente o cânone, ao mesmo tempo em que se busca resgatar do esquecimento as escritoras do séc. XIX, significa abrir caminho para que as diferenças sociais de gênero, classe e raça possam se inserir como elementos constituintes do discurso literário brasileiro, colocando em cena diferentes identidades presentes na cultura, na história e no espaço social e geográfico nacional.

Ao repensar o caráter excludente, fundante do paradigma nacionalista brasileiro, novas narrativas emergiram em diferentes esferas sociais, produzidas por novos sujeitos, antes considerados irrelevantes, que tomaram para si o poder do discurso, passando a se autorrepresentar. Sobre estes novos discursos, em especial os textos literários produzidos por mulheres, Schmidt (2019) afirma que eles "podem ser considerados contranarrativas do discurso assimilacionista brasileiro" (SCHMIDT, 2019, p. 78), pois, expõem as fissuras de projeto uniformizador que separou e excluiu memórias e identidades plurais em favor da criação de uma suposta identidade cultural homogênea de caráter totalizador e hegemônico. Frente a esse contexto, a literatura de autoria feminina tem buscado negar e deslegitimar mitos e fantasmas como o Anjo do Lar que, por tanto tempo, assombrou Virginia Woolf. Como Woolf, as mulheres escritoras têm trabalhado no sentido de romper com as forças destrutivas que as aprisionaram por tanto tempo, utilizando a literatura como instrumento para a construção de uma consciência livre sobre si mesmas.

\section{A autoria feminina e lugar de fala: a escrita como forma de resistência.}

A tradição ocidental ao longo dos séculos encarregou-se de construir o discurso responsável pela fixação de uma imagem feminina desenhada a partir da visão masculina eurocêntrica presente nas obras literárias que constituem o cânone. Trata-se de uma escrita totalizadora que apresenta personagens femininas idealizadas, submissas e inferiorizadas, posicionadas sempre à sombra do poder masculino. Na cultura contemporânea, graças às lutas das mulheres por 


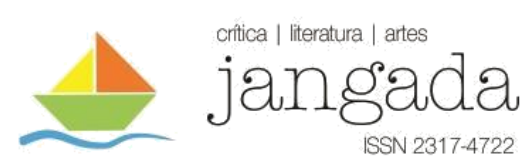

direitos e igualdade, tem sido possível o surgimento de um novo paradigma feminino disposto a contestar as normas e valores sociais norteadores das relações de gênero, raça e classe. $\mathrm{O}$ movimento de mulheres, bem como os movimentos negro, dos povos indígenas e da comunidade LGBT têm atuado de maneira organizada a fim de alcançar maior autonomia do pensamento e liberdade para criação de novas vozes capazes de ressignificar o discurso dominante que, por tanto tempo, tratou de definir as funções e os lugares que cada grupo e seus indivíduos deveriam ocupar na sociedade. Através da disputa pelo direito de poder falar por si, esses grupos têm atuado no sentido de subverter valores estéticos e ideológicos impostos pelo poder hegemônico que, usando o discurso como instrumento de dominação e controle, tratou de separar e excluir determinados grupos das funções e dos espaços privilegiados relegando-os à subalternidade e à marginalidade.

Foucault (1996), em sua teoria social do discurso, busca demonstrar o funcionamento da linguagem em sua existência socio-histórica, considerando as práticas sociais que sistematicamente constituem os objetos de que falam. Para ele o discurso não é apenas um conjunto de signos, nem é algo transparente e neutro, pois no seu processo de produção sofre interdições na medida em que está ligado ao desejo e ao poder. Para Foucault (1996), a produção dos discursos envolve procedimentos que limitam e controlam, de modo que não é permitido a todos os indivíduos falar de qualquer coisa em qualquer circunstância:

suponho que em toda sociedade a produção do discurso é ao mesmo tempo controlada, selecionada, organizada e redistribuída por certo número de procedimentos que têm por função conjurar seus poderes e perigos, dominar seu acontecimento aleatório, esquivar sua pesada e temível materialidade (FOUCAULT, 1996, p. 8-9).

Ao considerar a ocorrência não só das interdições, mas também a existência do que denomina de princípio de exclusão (separação e rejeição), Foucault acredita que o discurso não apenas manifesta (ou oculta) o desejo, mas é ele o próprio objeto do desejo. Para este autor "o discurso não é simplesmente aquilo que traduz as lutas ou os sistemas de dominação, mas aquilo pelo que se luta, o poder do qual queremos nos apoderar" (FOUCAULT, 1996, p. 10). Como em um jogo estratégico, o discurso é ao mesmo tempo palco e alvo de disputas de naturezas diversas em que palavras e imagens se materializam nos mais diversos formatos de textos que, por sua vez, irão produzir discursos representativos de instituições e grupos sociais. Esses 


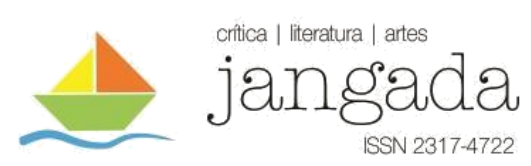

discursos são construídos através das práticas sociais que envolvem relações de poder e saber que são constantemente atualizadas à medida em que vão se dando as mudanças no tempo e nos espaços. Nesta perspectiva o discurso é resultado de disputas entre sujeitos e seus saberes, em que cada grupo produz suas verdades, seus sentidos e seu reconhecimento, em constante processo de busca de uma legitimação que permita veicular o saber e assim, gerar o poder.

O conceito foucaultiano de discurso tem contribuído para o entendimento de como as "verdades" são construídas, possibilitando assim reflexões importantes para a crítica literária no que diz respeito à representação de fenômenos diversos através da linguagem. No campo da produção literária brasileira, até meados do século XX, os discursos construídos no interior dos grupos sociais marginalizados (mulheres, negros, indígenas, LGBTs, moradores de periferia) ainda não haviam alcançado o estatuto da legitimidade que lhes proporcionasse o reconhecimento necessário para permitir sua circulação nos meios de divulgação e promoção da literatura. De acordo com Zolin (2009),

para ter assegurado o direito de falar, enquanto o outro é silenciado, o sujeito que fala se investe de um poder advindo do lugar que ocupa na sociedade, delimitado em função de sua classe, de sua raça e, entre outros referentes, de seu gênero, os quais o definem como o paradigma do discurso proferido. Historicamente, esse sujeito imbuído do direito de falar é de classe média alta, branco e do sexo masculino (ZOLIN, 2009, p. 106).

Passadas algumas décadas, atualmente, a produção literária dos grupos historicamente marginalizados tem possibilitado transformar os integrantes desses grupos, antes vistos como objetos do discurso, em sujeitos políticos, capazes de falar por si e de se autorrepresentar a partir de uma percepção própria de si e do mundo ao redor. Esse deslocamento tem tornado possível a ressignificação das identidades de gênero, raça e classe na medida em que, partindo de um lugar de fala (RIBEIRO, 2017), sujeitos que tiveram suas vozes historicamente interrompidas assumem o controle do discurso produzido sobre sua própria história, antes, apagada pelo discurso hegemônico.

Por lugar de fala entende-se o lugar social onde são produzidos os discursos. De acordo com Ribeiro (2017), a localização social proporciona experiências diferentes aos indivíduos podendo favorecer ou restringir oportunidades. Para exemplificar sua colocação, a autora aponta a condição da mulher negra na sociedade que, por conta de sua localização social, vai 


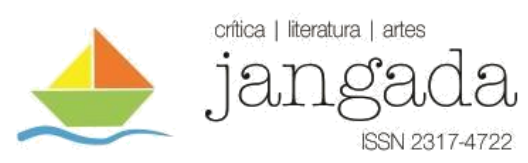

experienciar gênero de forma diferente de uma mulher branca. Assim, a teoria do lugar de fala permite refutar uma visão universal das identidades (étnicas, de gênero, etc), na medida em que visa promover uma multiplicidade de vozes com o intuito de romper com o discurso hegemônico tido como único e autorizado. Deste modo, de acordo com Ribeiro (2017), a assimilação do conceito de lugar de fala torna possível o desenvolvimento de estratégias capazes de interromper vozes hegemônicas, possibilitando a emergência das vozes que historicamente foram silenciadas. Em suas elaborações em torno das experiências comuns resultantes do lugar social ocupado pelas mulheres negras, Ribeiro (2017) demonstra que, aos serem impedidas de acessar determinados espaços como por exemplo, universidades, mídia, política, este grupo fica impossibilitado de produzir seu próprio pensamento, sua imagem, seu discurso, a ponto das vozes dos indivíduos pertencentes a este grupo não serem ouvidas.

Tendo em vista esta condição de silenciamento a que ficam submetidos certos grupos na sociedade, "o falar não se restringe ao ato de emitir palavras, mas de poder existir" (RIBEIRO, 2017, p. 64). De acordo com a autora, pensar o lugar de fala, nesta perspectiva, seria uma maneira de refutar a historiografia tradicional e a hierarquização de saberes decorrentes da hierarquia social. O rompimento com o estatuto do silêncio secularmente imposto às mulheres, às minorias étnicas e às classes sociais menos favorecidas abre caminho para que esses indivíduos falem por si mesmos, desestabilizando o discurso autorizado e criando tensionamentos com vistas para a transformação social. De acordo com Ribeiro (2017), a produção de discursos contra-hegemônicos visa desestabilizar a norma e pensar outras possibilidades de existências para além das impostas pelo regime discursivo dominante. Assim, "pensar lugar de fala seria romper com o silêncio instituído para quem foi subalternizado, um movimento no sentido de romper com a hierarquia, muito bem classificada por Derrida como violenta" (RIBEIRO, 2017, p.90).

No momento em que as mulheres tomam a palavra para si, tem início o movimento de resistência e de subversão dos códigos escritural/social/cultural de uma tradição literária que, por séculos, as havia relegado à condição do Outro da cultura. Sua representação, até este momento, deu-se a partir de uma concepção do que seria a mulher apenas enquanto corpo feminino, fundada em uma visão totalizante e equivocada, daí a necessidade de fazer surgir um movimento que fosse capaz de desconstruir o modelo feminino construído pelo patriarcado. Ao se apoderarem da escrita, as mulheres vão buscar se libertar do modelo essencializante de domesticidade, submissão e inferioridade que, por tanto tempo, as mantiveram aprisionadas. Com o intuito de negar e deslegitimar as estruturas repressivas e transformar o aparato Jangada | nr. 15, jan/jun, 2020 | ISSN 2317-4722 


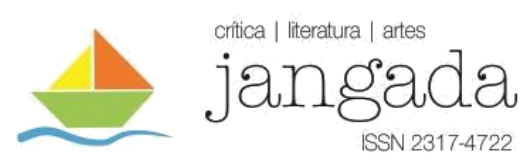

ideológico contido nas formas dominantes da cultura patriarcal, que determinavam as relações de poder entre os sexos, as narrativas produzidas por mulheres surgem com o intuito de construir uma nova consciência de si mesmas, colocando em xeque as representações tradicionais que vinculavam o corpo feminino apenas ao papel biológico de reprodução da espécie humana e a serviço da família e da vida doméstica.

Assim, a ficção produzida pelas mulheres tem buscado construir novos modelos que ofereçam possibilidades mais amplas e menos limitadas para a mulher na sociedade. Por meio da palavra, as escritoras vêm trabalhando no sentido de ressignificar seus anseios e desejos, seu corpo e sua existência enquanto sujeito que busca se fazer livre das amarras sociais e culturais, utilizando-se da palavra para externalizar as inquietações, a revolta contida e o desejo de liberdade através da imaginação criadora. Deste modo, a consciência da condição de oprimida, aliada ao poder que a palavra lhes proporcionou, faz ecoar uma voz narrativa muito diferente daquela entoada pela tradição canônica. De acordo com Susana Bornéo Funck (2016, p. 96) não se tem mais uma "estética da renúncia", uma "temática da invisibilidade e do silêncio", uma "poética do abandono". Para esta autora, a indignação deu às mulheres escritoras um instrumento de conscientização. O feminino, como passividade e conformidade, dá lugar a uma nova ação narrativa que inclui ação e questionamento. A representação da mulher na literatura que, antes, na tradição literária, era feita a partir de uma perspectiva masculina que diminuía ou excluía as mulheres, levando em conta apenas os seus significados construídos e perpetuados pela cultura passa a ser questionada, e em seguida, reformulada pelas escritoras, que passam então a falar por si mesmas, afastando-se da visão essencialista, colocando em xeque o conceito de "mulher" como uma categoria homogênea.

São colocadas em cena identidades femininas plurais, considerando-se a interseccionalidade ${ }^{6}$ entre as categorias de gênero, classe social e raça. Identidades constituídas a partir de experiências diversificadas, fazendo nascer na literatura personagens que subvertem o modelo imposto e que buscam romper com os limites instituídos pelo poder patriarcal. Neste

\footnotetext{
${ }^{6}$ De acordo com Djamila Ribeiro (2018), o conceito de interseccionalidade foi cunhado em 1989, por Kimberlé Crenshaw em sua tese de doutorando. Segundo Kimberlé, a interseccionalidade "trata especificamente da forma pela qual o racismo, o patriarcalismo, a opressão de classe e outros sistemas discriminatórios criam desigualdades básicas que estruturam as posições relativas de mulheres, raças, etnias, classes e outras" (CRENSHAW apud RIBEIRO, 2018, p. 123). No entanto, antes mesmo deste conceito ter sido cunhado, várias feministas negras, dentre elas bell hooks e Angela Davis, já se utilizavam da análise interseccional para pensar o modo como as opressões se combinam e se entrecruzam, gerando outras formas de opressão. Davis (1981), por exemplo, em Mulheres, raça e classe, já enfatizava a necessidade de utilizar outros parâmetros de feminilidade, denunciando o racismo existente no movimento feminista. Para Ribeiro (2018), pensar a interseccionalidade permite compreender que raça, classe e gênero são categorias indissociáveis e não podem ser pensadas isoladamente.
} 
ponto, as mulheres escritoras irão partir das experiências pessoais femininas para transformálas em ficção, a fim de desestabilizar os arranjos sociais naturalizados pela cultura ao longo do tempo.

Na medida em que se percebe o quanto a atividade literária está marcada por diferenças de gênero, vão surgindo as produções literárias de escritoras preocupadas em desautorizar as narrativas mestras da cultura. Estas escritoras irão problematizar as convenções sociais, antes aceitas como fruto da ordem natural das coisas e não como construções historicamente determinadas. Neste momento cria-se a oportunidade para a reformulação do estatuto da representação (e da autorrepresentação) e, por conseguinte, para a alteração dos parâmetros que, até então, nortearam a construção das identidades de gênero.

Funck (2016), em seus estudos sobre obras produzida pela escritora canadense Anna Swan e pelas inglesas Angela Carter e Jeanette Winterson na década de 1980, aponta que:

conforme a teoria feminista começa a explorar questões como identidade de gênero e a contestar a experiência vivida enquanto base política, a ficção produzida por mulheres passa a contemplar um novo conceito de representação, baseado na excentricidade e no espetáculo, com ênfase no caráter performativo da identidade de gênero e na provisionalidade das noções de feminino e masculino (FUNCK, 2016, p. 211).

A autora segue em sua explicação, demonstrando que:

Se, durante as décadas de 1960 e 70, muitas escritoras buscam transformar suas experiências pessoais em ficção (Silvia Plath e Marge Piercy, por exemplo) ou narrativizar seu sonho utópico de uma sociedade sem hierarquias de gênero (como Ursula LeGuin e Joanna Russ), já, na década de 1980, podese perceber um esforço no sentido de uma mudança que busca desestabilizar arranjos sociais naturalizados por meio de narrativas que fazem uso do grotesco e do insólito (FUNCK, 2016, p. 211-213).

Em relação ao conceito de gênero, importa considerá-lo e compreendê-lo enquanto elemento que é parte de um processo de construção social e cultural, que envolve relações assimétricas de poder. A desigualdade de gênero não se refere apenas à diferença sexual, mas sim à relação de dominação do feminino pelo masculino, por essa razão não deve ser tratada 


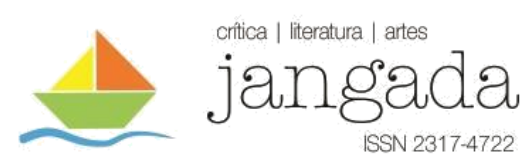

como categoria isolada. Nesta perspectiva, o texto literário passou a ser visto, em relação ao discurso hegemônico, como um instrumento de ideologia e como um dos lugares onde a subjetividade é construída.

Assim, a partir do revisionismo crítico da produção literária canônica, dos conceitos básicos do estudo literário e das teorias que haviam sido formadas a partir do viés masculino, as mulheres escritoras, apoiadas pelo movimento e pelas teorias políticas do feminismo, passam a reivindicar o reconhecimento da produção literária feminina. Empenhadas em redefinir as construções sociais e culturais relativas ao gênero, que, ao longo da tradição tratou de colocar as mulheres em condições desvantajosas na sociedade, as escritoras apoderaram do discurso literário e passaram a utilizá-lo como instrumento a favor da luta pela igualdade e por direitos. Deste modo, a apropriação feminista da literatura é um gesto político, visto que a exclusão das mulheres, assim como de outros grupos sociais marginalizados do estatuto literário expõe o sexismo, o racismo e o classismo como práticas ideológicas hegemônicas.

\section{CONSIDERAÇÕES FINAIS}

No que se refere à literatura, o esforço das escritoras em subverter as normas de representação do feminino a partir da recusa dos papéis sociais historicamente impostos às mulheres tem permitido o surgimento de um discurso literário que opera a favor da descentralização do sujeito do feminismo ao se contrapor à ideia de uma suposta universalidade, continuidade e unicidade deste sujeito. Ao levar em conta as sexualidades não hegemônicas, como também a intersecção entre raça, etnia, classe, nacionalidade, faixa etária, dentre outras categorias que atuam na construção das identidades, a escrita tem se mostrado uma ferramenta importante para o entendimento do processo de identificação dos gêneros, responsável por imprimir um caráter transgressor e político à narrativa de autoria feminina. Trata-se da tentativa das mulheres escritoras de livrarem-se dos sistemas, hierarquias e valores masculinos e alcançar a natureza primária e verdadeira da sua condição, agora autodefinida através da sua própria experiência cultural, levando em consideração as variantes significativas de classe e grupo étnico. Ao questionar as assimetrias de poder relacionadas às categorias de gênero, classe e raça, a prática literária feminista adquire força política e as identidades passam a ser entendidas como plurais e ambivalentes, em um movimento que parte da negação da ordem estabelecida, a fim de criar novas possibilidades de reinvenção do sujeito que, deixa de ser objetificado. 


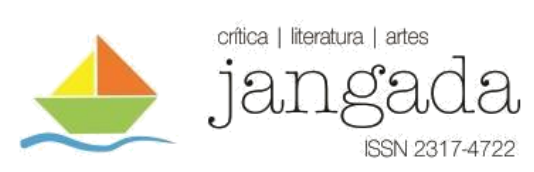

Neste novo espaço conceitual, o carácter naturalizado dos arranjos de gênero e dos modelos de identificação, até então reconhecidos, passam a ser desnaturalizados (ou descontruídos), na medida em que se adquire a compreensão da categoria identitária de gênero como múltipla e provisória. As noções de corpo e de gênero são repensadas e aparecem reformuladas a fim de romper com as oposições binárias entre o cultural e natural e entre o feminino e masculino. $\mathrm{Na}$ arena literária, comportamentos historicamente cristalizados aparecem representados de maneira a transgredir as regras e os modelos até então vigentes, como tem demonstrado a literatura produzida pelas mulheres escritoras.

\section{REFERÊNCIAS BIBLIOGRÁFICAS:}

DUARTE, Constância. O feminino fragmentado. In: Ipotesi, Juiz de Fora, v. 13, n. 2, p. 31 37, jul./dez. 2009.

DUARTE, Constância Lima. A imprensa feminina e feminista no Brasil: Século XIX. Belo Horizonte: Autêntica, 2016.

Feminismo: uma história a ser contada. In: Pensamento Feminista Brasileiro: formação e contexto. HOLLANDA, Heloisa Buarque de (Org.) Rio de Janeiro: Bazar do Tempo, 2019.

DUARTE, Constância Lima; PAIVA, Kelen Benfenatti. A mulher de letras: nos rastros de uma história. In: Ipotesi, Juiz de Fora, v. 13, n. 2, p. 11-19, jul./dez. 2009. Disponível em: http://www.ufjf.br/revistaipotesi/files/2009/10/a-mulher-de-letras.pdf Acesso: 10/12/2019

FUNKC, Susana Bornéo. Crítica literária feminista - uma trajetória. Série Estudos Culturais. Florianópolis: Insular, 2016.

RIBEIRO, Djamila. O que é lugar de fala? Belo Horizonte (MG): Letramento: Justificando, 2017.

. Quem tem medo do feminismo negro? São Paulo: Companhia das Letras, 2018.

SCHMIDT, Rita Terezinha. Na literatura, mulheres que reescrevem a nação. In: HOLLANDA, Heloisa Buarque de (Org.). Pensamento Feminista Brasileiro: formação e contexto. Rio de Janeiro: Bazar do Tempo, 2009.

WOOLF, Virginia. Profissão para mulheres e outros artigos feministas. Porto Alegre, RS; L\&PM, 2016.

ZOLIN, Lúcia Osana. A literatura de autoria feminina no contexto da pós-modernidade. In: Ipotesi, Juiz de Fora, v. 13, n. 2, p. 105-116, jul./dez. 2009. Disponível em: http://www.ufjf.br/revistaipotesi/files/2009/10/a-literatura-de-autoria-feminina.pdf Acesso: $10 / 12 / 2019$ 